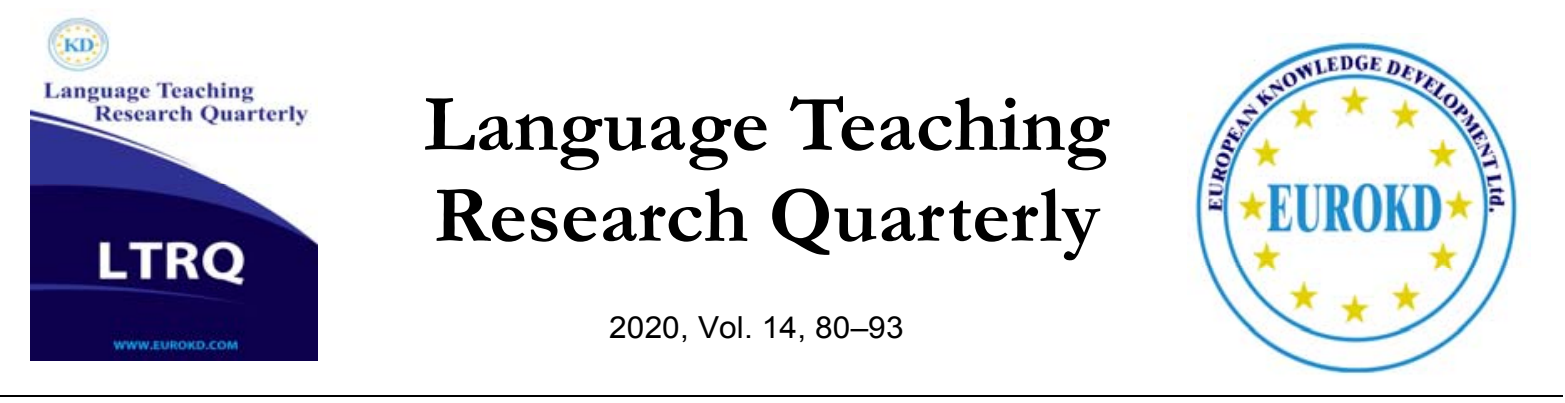

\title{
Encouraging Extensive Listening in Language Learning
}

\author{
Demet TURAN ÖZTÜRK, Süra TEKiN \\ Niğde Ömer Halisdemir University, School of Foreign Language, Turkey
}

Received 19 June 2019 Accepted 09 November 2019

\begin{abstract}
This study aims to generate an analysis of how to encourage extensive listening in an English Preparatory Program with listening worksheets in an enjoyable way, to identify the learners' responses, and to establish the feedback from students which could provide more productive activities. For many of the students listening in target language is a challenging task. Extensive listening aims to get the learners listen and enjoy it. To improve the listening fluency, extensive listening is one of the functional and practical ways thanks to easy and interesting materials. Extensive listening encourages the learners to get fluent in a qualified way. The main value in extensive listening is to allow the students' self-selection and the decision of how to spend time effectively to improve their listening skill in the target language. 6 Turkish learners of English were the participants of this study; and they completed worksheets after each listening activity for 5 weeks in the spring term of 2018-2019 academic year in the prep school of a state school. The results of the analyses showed that all of the participants showed positive tendency towards listening and they developed their level of listening skill, along with some other skills in the target language.
\end{abstract}

Keywords: Extensive Listening, Listening for Pleasure, Prep Schools

\section{Introduction}

Listening is one of the main skills in the learning process and crucial ways for the language learners. This skill enables us with different perspectives. One of the receptive skills, listening builds relationship with the other cultures and empowers our vision and provides meaningful output, speaking. Waring (2010), "If you understand almost all of the text you listen to, you can build your word recognition speed, you'll notice more uses of grammar points, more collocations and generally your brain will be working very effectively." 
Purdy (1997) explained listening as "the active and dynamic process at attending, perceiving, interpreting, remembering, and responding to the expressed needs, concerns, and information offered by other human being" (p.8).

For many of the students listening in target language is a challenging task. Speed of the conversation, unfamiliar words, and lack of contextual knowledge, concentration and learning habit are some of the weaknesses for most of the language learners. Extensive listening aims to get the learners listen and enjoy it. The main reason is for pleasure and enjoyment and it is a practical way in language learning. Accurate and fluent listening are the essential points of extensive listening. To improve the listening fluency, extensive listening is one of the functional ways thanks to easy and interesting materials. The extensive listening enables teachers to encourage the learners to be glad to listen. These materials need to be easy and available with various topics related to the learners' interests. Choosing comprehensible, personally interesting, attention-drawing and meaningful listening materials is a must to fulfill extensive listening with language learners (Renandya, 2012). The crucial value in extensive listening is to allow the students' self-selection and the decision of how to spend time effectively to improve their listening skill in the target language. For language learning, extensive listening encourages the learners to get fluent in a qualified way. The aim of extensive listening is to improve learners' "listening fluency", which is considered to help learners to develop "automatic processing of the target language", on the condition that it is done in a proper way (Waring, 2008, p. 8).

The purpose of this qualitative study is to generate an analysis of how to encourage extensive listening in an English Preparatory Program in an enjoyable way, to identify the learners' responses, and to establish the feedback provided by students which could be improved to provide more productive activities through listening and could be suggested for the curriculum. The study seeks to answer the following research questions:

1. What are the learners' perceptions about extensive listening?

2. Does extensive listening have an effect on learners' listening skill development? If yes, how does it affect it?

\section{Review of Literature}

Listening is the one of the main skills in language learning. Listening in target language is a challenge for the Turkish language learners, especially for the lower-level learners, due to lack of exposure of authentic materials. As Riddell (2003) mentioned, listening is one of the most difficult activities for most students. Therefore, exposure of target language is a must in language learning process to experience a real and natural usage of language. Renandya and Farrell (2011) claim that "listening is best learned through listening" (p. 56). Krashen (1985) explains that language acquisition is best achieved by understanding input in the form of messages. In order to understand oral messages, one's listening comprehension skill needs to be well-improved. According to Hunsaker (1990), more than three quarter of students' learning in the classroom is available through listening. Dupuy (1999), for instance, investigated her lower proficiency learners of French as a foreign language and as a result it was only possible following that the 
learners listened to the same listening material three or four times. Gilbert (2005) also conducted a study to analyze the effectiveness of listening skill. He noted that K-12 learners used between $60 \%$ and $90 \%$ of the classroom time listening, which means they learn mainly through listening. Rost (1994) emphasizes the importance of listening in language classrooms in terms of input, interaction, authenticity and learning the language forms. He explains that listening is an essential skill which provides the necessary input to learn a language. It also fosters the interaction of learners and helps them achieve understanding better. Learners are able to hear and get familiar to the authentic spoken language, which is used by native speakers. Finally, learners are exposed to the usage of language forms such as grammar and vocabulary with the help of listening.

Extensive listening is one of the methods to improve listening fluency with enjoyment and pleasure. The extensive listening process needs time and effort. Extensive listening, which is defined by Rixon (1986) as listening for pleasure and related to their own interest regardless of considering the details, is seen as a functional way to develop listening comprehension and other language skills. Extensive listening (EL) is also described as an "individualized listening activity with large amounts of target language input of learners' interests and at their levels" (Yeh, 2017, p. 88). Nation (2008) mentions that "listening skills will improve when the learners engage in meaning-focused input and fluency development tasks that include extensive listening to easy and interesting material". The main points of extensive listening are the self-selected listening materials and focusing on meaning while listening (Schmidt, 2016). Moreover, learners are able to choose how many times to listen to the tracks in extensive listening activities.

Extensive listening has essential benefits for various language skill areas, such as vocabulary development, productive skills, especially pronunciation and speaking and motivation for learning (Renandya \& Farrell, 2010). Ucan (2010) conducted a study and concluded that extensive listening is helpful for the students to develop their vocabulary competence, listening comprehension, and make them feel more comfortable. Moreover, Antle (2011), in a study with 35 Japanese university students indicated that extensive listening had a positive relationship on reading speed. Onoda (2012) also studied the effects of extensive listening on listening skills and students' self-confidence. He found that extensive listening improves students' both listening abilities and self-confidence. The improvement of language comprehension is another benefit of extensive listening, as it leads learners to get closer to language acquisition (Renandya, 2012). Learners also find the opportunity to reflect on their listening by identifying their strong and weak features, and have an idea about which skills to work on and improve in or out of the classroom (Schmidt, 2016). As learners choose their own listening materials in extensive listening, they can develop autonomous learning features such as taking the control of their own learning, having responsibility for their own learning and practicing their decision-making abilities.

Day and Bamford (1998) explain the features of an extensive listening program from various perspectives. For instance, listening occurs primarily outside of the classroom and with students' choice of content, level, pace and times to listen. They can also choose the genre of the listening 
activity based on their interest and listen for different aims with different methods. Extensive listening is related to general understanding or pleasure. Teacher's role in the implementation of extensive listening programs should be of a guide's, who explains the purpose and methodology of the process. Brown, Waring, and Donkaewbua (2008) suggested that a considerable amount of vocabulary knowledge was gained from the exposure, but was not assessed. Such knowledge might include the noticing of lexical phrases, collocational and colligational patterns, new nuances of meanings, improved lexical access speed, and so on. It is probably here that the true benefit of reading and listening extensively occurs. (p. 158). "Practice is the most important thing. The more listening the better, and the subskills will take care of themselves as they become automatized." Renandya and Farrell (2011, p. 56) suggested a similar belief: "just like reading, listening is best learnt through listening."

\section{Methodology}

The aim of this study is to encourage extensive listening for pleasure and find out whether or not it would lead to improvement of the learners' listening skill. The methodology of this study was kept within the border of qualitative and quantitative research considering the features of mixedtype research design. In parallel, this qualitative research study was situated within an exploratory case study to better understand the perceptions of the learners' about extensive listening. Analyses of the participants' grades were the quantitative data. The case study allows a researcher "to discover context characteristics that will shed light on an issue or object" (Sanders, 1981, p. 44).

The participants are 6 Turkish learners of English and they take English course at the School of Foreign Languages at a state university in Turkey. The study was conducted in the spring term of 2018-2019 academic year. The researchers asked for the volunteer students who would want to take part in this study. The participants are provided with an audio list and websites. The learners listened to various topics related to their own interests and completed worksheets about these listening activities. Data of this study were collected from the interviews with the participants, worksheets which participants completed after the listening activities, listening quiz scores of the participants and researchers' observations about extensive listening. Throughout the first and second term of 2018 - 2019 academic year the students were tested and evaluated by four main types of assessment including midterm 1, midterm 2, quiz averages and portfolio. In this study learners' listening part in each assessment were analyzed by the researchers whether there were any improvements in learners' listening skills. For the qualitative data, content and frequency analysis were used and for the quantitative data, students' grade were analyzed to observe if there were any improvements. After transcribing and translating the interviews, the transcriptions were analyzed thoroughly, and the key concepts that occurred frequently in the interviews were highlighted and coded with the help of content analysis method. Content analysis is a qualitative research analysis which is used to analyze textual materials, such as interviews, journals, observations, media products etc. Mayring (2000) defines the main idea of this procedure as "the formulation of a criterion of definition, derived from theoretical 
background and research question, which determines the aspects of the textual material taken into account". As the material is reduced to some extent in content analysis, it is clearer and unambiguous compared to other methods of data analysis (Flick, 2009).

\section{Results}

This study aimed to find out the learners' perceptions about extensive listening and propose suggestions to make use of these kinds of activities by integrating them into their language learning process. To fulfill this aim, data were collected from various sources and analyzed. These data collection tools of this study are the interviews which are conducted with the participants, worksheets which participants completed after the listening activities, listening quiz scores of the participants and researchers' observations about extensive listening.

\section{Interviews with Participants}

Participants were interviewed after they completed their extensive listening activities. Their answers were recorded and transcribed. Content analysis method was utilized in order to come up with the themes about participants' thoughts and perceptions as to the process. The questions and themes which are categorized as strengths and weaknesses are listed below.

Q1: What do you think about listening out of the classroom?

Table 1

Themes from the answers of the first interview question

\begin{tabular}{ll}
\hline Strenghts & Weaknesses \\
\hline - fruitful $\# 2$ & - tiring \\
- understanding instructors better & - lack of enough vocabulary \\
- controlling the external factors & \\
- satisfying & \\
- more effective with text & \\
- appeals to every student & \\
\hline
\end{tabular}

The themes which are gathered from the answers of the first question are mostly positive (Table 1). Two participants thought that this process was fruitful for their English learning process. One participant stated that she understood the instructors better in the classroom since the beginning of this process. Another participant expressed that he was able to control the external factors while listening such as volume and how many times to listen to the track in order to understand it better; because there were not any outer disturbing noises or time limitations, and he was able to listen more carefully on his own.

"I just put on my earphones and get away from the world. I can just focus on listening without any outer noises."

This fact contributed positively to his perception of listening out of the classroom for pleasure. One of the themes which was gathered from the first question was that it was a satisfying process for the participant, and the participant was happy to be a part of this study. 
Also, it was thought that the extensive listening activity was more effective with the transcript on her hands. The theme that it appeals to every student is one of the most powerful aspects of the extensive listening activities, as each student has the opportunity to choose a specific topic to listen for pleasure. By this way, they are more interested in listening and complete the activities without any time or topic limitation.

"I started to dream in English."

"Now I'm more interested in searching for the lyrics of the songs which I like. And I have been learning more words from them."

"As the listening tracks were short, I completed them and the worksheets in a short time and it wasn't boring for me. I had fun."

Only two negative themes emerged from the content analysis of the answers to the first interview question. The first one is that extensive listening was a tiring activity for one of the participants. The reason for this theme might be the fact that this participant did not complete the listening activities regularly and tried to finish them in a short time, which causes the participant to think that it was a tiring process. Another participant stated that the lack of enough vocabulary knowledge had a negative effect on her perception of the listening activities, because it made it harder for her to understand the listening tracks better.

"When I don't know a word in the track, I get distracted. I understand the general theme of the listening track, but I don't know the word..."

Q2: Please describe your extensive listening process with three adjectives.

Table 2

Themes from the answers of the second interview question

\begin{tabular}{ll}
\hline Strenghts & Weaknesses \\
\hline - helpful $\# 2$ & - boring without the text \\
- challenging $\# 2$ & - difficult \\
- fruitful $\# 2$ & \\
- effective & \\
- successful & \\
- beautiful & \\
- manageable & \\
- engaging & \\
- fun & \\
\hline
\end{tabular}

Table 2 shows themes which are gathered from the answers of the second question of the interview. It aimed to gather the description of the participants' perceptions about the extensive listening process with adjectives. The mostly used adjectives here were "helpful", "challenging" and "fruitful". Participants generally used positive adjectives to describe their experiences. The participants who thought that it was a helpful process claimed that it was helpful for various aspects of their language learning process such as vocabulary, reading skill, pronunciation, comprehension of the in-class interactions and listening skill itself. They stated that completing and achieving such an activity was an encouraging source of motivation for themselves. The fact that it was challenging was regarded as a positive side of this study by the participants. They had 
the opportunity to move one step beyond their current state of knowledge about and acquisition of the language, as Krashen (1988) defines in his "Comprehensible Input" hypothesis. Similarly, two participants stated that it was a fruitful process for their listening skill development, and one participant said that it was effective way to study listening. One of the participants stated that she felt she was successful at listening. The participant who claimed that the activities were manageable constituted a positive perception as to the extensive listening, and so did the participants who expressed that it was engaging and fun. In a parallel way, in their study, Reinders and Cho (2010) came to the conclusion that students were free of the pressure which "they often experienced in class or the expectations as with 'regular' homework".

The weak points of extensive listening activities seem to be about transcript of the listening tracks and that it was a difficult process. Only one of the participants stated that the listening activities were boring without the transcripts. However, the aim of the listening activities in this study was to be able to listen for pleasure; therefore, there was no need for a transcript. The participant who thought it was difficult had difficulties in completing the worksheets, however she expressed that the listening tracks were short and easy for her.

Q3: How do you think extensive listening has affected your language learning?

Table 3

Themes from the answers of the third interview question

\begin{tabular}{ll}
\hline Strenghts & Weaknesses \\
\hline - positive contribution \#3 & --- \\
- permanent vocabulary learning & \\
- understanding texts faster \\
- vocabulary knowledge is important \\
- visual support might be better \\
- willingness to communicate \\
- becoming familiar with listening \\
- good for pronunciation
\end{tabular}

The third question of the interview was asked in order to gather information about the effect of extensive listening on the participants' language learning process, as it can be seen in Table 3 . Generally, the effects were not only on the listening skill itself, but also on the pronunciation, vocabulary knowledge and reading skills. Three participants reported that extensive listening had a positive contribution on their language learning. Permanent vocabulary learning was one of the most essential themes of this question's answers. The reason of permanent vocabulary learning might be the voluntary and eager listening for pleasure, because participants wonder about the meaning of a specific word and look up their dictionaries to find out about it. Understanding texts faster is an indicator that extensive listening activities contributed to the development of reading skill of the participant. Likewise, Antle's (2011) study shows that extensive listening affected participants' reading speed in a positive way. A similar result can be seen in the themes of the second question's answer. The participant who claimed that the vocabulary knowledge was important meant that without enough vocabulary knowledge, it was difficult to understand 
the listening track. The theme about visual support was about the preference of videos over tracks. That participant expressed that videos were more helpful to understand the context than tracks. One of the participants expressed that he had been more willing to get into communication in the classroom and become more familiar with the listening skill since the extensive listening activities started.

"Now I feel that I can understand the instructors better in the classroom"

"I want to get into the communication more in the classroom."

The theme that indicated the study was good for pronunciation is a similar one to the answers of the second question of the interview. None of the participants mentioned a negative effect of the extensive listening activities.

\section{Participants' Suggestions}

At the end of the interview, participants were asked for their suggestions about the use of extensive listening activities. The suggestions were grouped under five categories as "it should be an in-class activity (\#5), "it should be an out-of-class activity", "it should be based on voluntariness", "it should include the topics which the instructor chose for us" and "there should be more topics to choose from".

The majority of the participants claimed that extensive listening should be an in-class activity, which demonstrates that participants developed a positive perception about these activities, and they think that it would be more helpful for them to make use of this activity in the classroom.

"It should be an in-class activity, as it is where we learn English. I think it will be more beneficial with your (the instructor's) help."

Only one participant suggested that it should be an out-of-class activity. Reinders and Cho (2010) stated in their study that "extensive listening practice is difficult to do in class for practical reasons, and the classroom may not be the best place if the aim is to get students into the habit of engaging with the language on their own and to encourage them to take ownership of their practice".

"It should be conducted out of class, because we don't have enough time for it in the classroom."

"I think, the in-class listening activities are usually boring."

The reason for this suggestion might be the freedom that listening for pleasure provides for the learners, as they were able to choose any topic they wanted. Although a participant thought that it should be based on voluntariness, another one stated that it would be more effective if the instructor chose the listening activities for themselves.

"We should choose the topics of the listening activities by ourselves, by this way we have more fun while listening. They can be about football or series."

One participant stated that there should be more listening topics to choose from; so that they can pick the ones that they are really interested in.

"It would be better if we had more topics to choose, and we could have more freedom to listen for fun.” 


\section{Worksheets}

Another data collection tool of this study was the worksheets which the participants completed after each extensive listening activity. The worksheets included three steps which are prelistening, while-listening and post-listening; and various kinds of questions such as true-false questions, one-sentence summary etc. All of the participants completed these worksheets during the study; however, how regularly the worksheets were done was the determinant question at this point. Three participants did the worksheets on a daily basis. These participants' interview reflected a positive attitude towards the extensive listening activities.

"I think it contributed to my listening skill, as I completed the exercises regularly."

"It would have been better if I did it regularly."

\section{Results of Listening Quizzes}

The listening quizzes which were conducted through participants' extensive listening process were also evaluated with the aim of gaining an insight into how they affected participants' listening skill development. The participants took four quizzes in the duration of the study. The results of these four quizzes indicated that there was a general increase in the scores of participants. For instance, participant A showed an increase of \%58 in his listening quiz scores of these four quizzes. Participants B, C and D increased their scores in the rate of $\% 30$.

\section{Researcher's Observation}

Finally, the researcher's thoughts and beliefs which were based on her observation of this process were asked as part of the data collection process. Her views about extensive listening activities and the participants' perceptions were generally positive. She expressed that willingness about and interests in the listening skill were higher than before the time participants first started doing these extensive listening activities. The increasing scores of the participants' listening quiz results support this view of the researcher.

"All of the participants stated that they wanted to continue doing the listening activities in the summer holiday."

Individually, she stated about the participants that "participant A is an already motivated student", "participant B has started to show interest in the lesson, and her quiz scores increased", "participant $\mathrm{C}$ is more willing to learn" and "participant $\mathrm{D}$ expects negative quiz results first, but she gets good results eventually".

\section{Discussion and Conclusion}

This study aims to find out the effects of extensive listening activities on English learners' listening skill development and perceptions. The findings of this study revealed that the participants' perceptions as to the extensive listening are generally positive. Listening for pleasure and having the opportunity and freedom to choose which topic to listen to could be effective on this positive result, along with voluntariness of the participants. Student ownership is considerably encouraged through this method. In this study, participants were able to choose 
what they wanted to listen to freely, by considering their own linguistic and comprehension level, either consciously or unconsciouly. This freedom to choose their own material and its benefits to learners are in line with Oxford's (2011) self-regulated behavior theory, which emphasises the importance of learners' control of their own learning. Learners find the motivation and enthusiasm by doing an activity of their own choice(Onoda, 2012; Oxford, 2011).Widodo and Rozak (2016) support this view and claim that extensive listening helps learners promote their learner autonomy level by encouraging them to get into reflective actions in their own learning process. Chang and Millett (2013) found out in their study that suitable listening materials for learners's competence level is a source of motivation for them to continue listening. Learners also find the opportunity to listen to the tracks multiple times at their own pace and make the most of a listening activity by this way, rather than doing an activity which has been imposed by the teacher (Mayora, 2017).

The use of technology in this process, such as PCs or smart phones, might be another reason why participants were more interested and motivated to accomplish the listening activities. By emphasizing the usage of technology in extensive listening, Vo (2013) suggests that online resources both promote the learner interaction and help teacher monitor the learners' progress.

Participants' suggestions for the in-class use of these activities also reflect their willingness to continue these exercises, mostly in the classroom.

The findings of the study show that extensive listening activities were beneficial for the participants' language learning not only in terms of the listening skill and getting beyond their current level, but also for further exposure and input of the target language, better pronunciation, development of the reading skill and vocabulary knowledge, eagerness to get into the communication and interaction more in the classroom. "In an EFL context where exposure to the target language is limited, extensive listening is crucial for language development" (Vo, 2013, p.36), which is a general situation in the foreign language learning programmes. In addition, this result indicates a similarity to Antle's (2011) study, which was conducted with 35 Japanese university students, and which shows that extensive listening had a positive effect on participants' reading speed. Similarly, Ucan (2010) mentioned that extensive listening is fruitful for the students to improve their vocabulary competence, listening comprehension, and make them feel more comfortable about language learning. Moreover, Reinders and Cho (2010) claimed that extensive listening activities are helpful to increase learners' motivation lower their affective filter.It has also been claimed that "L2 learners' listening skills gained from EL can be transferred to listening to unfamiliar passages" (Chang \& Millett, 2013, p.37). Some other benefits of extensive listening might be listed as "independent learning, listening outside of the four-wall classroom, technology as a window of an open-access library, and language and knowledge enhancement" (Widodo \& Rozak, 2016, p.240).

In addition, how regularly the activities are done also have an effect on developing the listening skill and the perception about it. The regularity of the activities help improve the comprehensibility, which is a consequence of extensive listening (Chang \& Millett, 2016; Holden, 2008). The participants who did the activities regularly have more positive views about 
this process. Two of these participants, participant $\mathrm{A}$ and participant $\mathrm{C}$, are the ones who expressed that they did the worksheets regularly. Moreover, listening quiz results indicate a rise in the scores of four of the participants. Finally, the researcher states that she observed the willingness, interest and higher listening scores of participants throughout the extensive listening activities. All these consequences demonstrate that extensive listening has an effect on learners' developing their listening skill and a positive attitude towards listening in their language learning process.

The negative themes which were gathered from the content analysis, such as "challenging" and "tiring" do not necessarily mean the participants' negative perceptions about the extensive listening process. It should be considered as a normal process that learners feel a little disturbance for something they try for the first time in language learning. For instance, Yeh (2017) found that participants in her study had gone through similar challenges while doing extensive listening activities.Also, Chang (2010) studied how extensive listening activities affected participants' listening anxiety. Her results showed that the extensive listening group was more successful than the formal instruction group about listening competence, but their anxiety score increased significantly. The researcher concludes that it is facilitative anxiety, which provides a contribution to learners' learning the target language.

As a result, extensive listening aims to get the learners listen and enjoy it at the same time. Siegel (2011) expresses that including extensive listening into listening training is advantageous. As it is clear from the findings of this study, extensive listening has various benefits for language leaarners. This study indicates that extensive listening for pleasure has a positive effect on learners' listening skill and perception development. Exposure to different kind of listening materials helped the learners to develop and consolidate their one of the receptive skills. They refreshed their own vocabulary. It is observed from their worksheets that English language learners practicetheir skills in a meaningful and productive way. The researcher also observed the improvement of the learners' speaking skill. The learners gained pleasure from listening materials and activities. Some of the participants mentioned the necessity of more extensive listening and practices. During the main courses they expressed the lack of practices and time. The use of extensive listening could be effective as it is an opportunity to get more real life experience. These kind of listening activities are enjoyable and entertaining. The learners have the freedom of choice and that contributes to the students' satisfaction with the process. There are possible challenges which the teachers and learners may encounter, however there is always a way to solve the problems. The tasks in this study encouraged learners to focus on the process instead of directly answering the questions.

\section{Implications and Suggestions for Future Research}

The results of this study might be used by administrators, curriculum developers and instructors who work at prep schools, with the aim of encouraging and leading learners to listen extensively for pleasure. Course book choices might also be considered and shaped in terms of these results. 
In addition, students could be given more time, opportunity and resources to take up extensive listening for pleasure in and/or out of the classroom.

This study was conducted in only the prep classes of a school, but it might be conducted in more School of Foreign Languages to be able to generalize the results and come up with a more reliable conclusion. Likewise, the participants might be chosen from all the classes in a prep school, not only the ones that the researcher teaches. Also, not only the volunteer students, but all of the students in a prep school might be the participants of this study. A similar study may also be conducted with students who have different levels of English proficiency. A similar study might be implemented without time limitation. In addition, encouraging learners to use technology more with the aim of listening extensively seems to be a rational way in improving their language learning by fostering student ownership. For instance, podcasts, YouTube videos, Ted talks, or the lyrics of their favorite songs definitely make interesting sources of extensive listening for learners. Apart from these alternatives, more studies could be implemented which search for the difficulties that the learners face while listening and solutions to overcome them to be better listeners in the target language.

\section{References}

Antle, J. B. (2011). Extensive listening and how it affects reading speed. In A. Stewart (Ed.), JALT2010 Conference Proceedings. Tokyo: JALT

Chang, A. C. S. (2010). Second-language listening anxiety before and after a 1-Yr. intervention in extensive listening compared with standard foreign language instruction. Perceptual and Motor Skills, 110(2), 355365. https://doi.org/10.2466/pms.110.2.355-365

Chang, A. C., \& Millett, S. (2013). The effect of extensive listening on developing L2 listening fluency: Some hard evidence. ELT journal, 68(1), 31-40.

Chang, A. C., \& Millett, S. (2016). Developing L2 listening fluency through extended listening-focused activities in an extensive listening programme. RELC Journal, 47(3), 349-362.

Day, R. R., Bamford, J., Renandya, W. A., Jacobs, G. M., \& Yu, V. W. S. (1998). Extensive reading in the second language classroom. RELC Journal, 29(2), 187-191.

Dupuy, B. C. (1999). Narrow listening: An alternative way to develop and enhance listening comprehension in students of French as a foreign language. System, 27, 351-361.

Flick, U. (2009). An introduction to qualitative research. London: SAGE.

Gilbert, M. B. (2005). An examination of listening effectiveness of educators: Performance and preference. Professional Educator, 27(1/2), 1-16.

Holden, W. R. (2008). Extensive listening: A new approach to an old problem. Journal of the Faculty of Humanities, University of Toyama, 49, 299-312.

Hunsaker, R. A. (1990). Understanding and developing the skills of oral communication: Speaking and listening (2nd ed.). Englewood, CO: J. Morton Press.

Krashen, S. D. (1985). The input hypothesis: Issues and implications. Beverly Hills, CA: Laredo Publishing Company.

Krashen, S. D. (1988). Second language acquisition and second language learning. Prentice-Hall International.

Mayora, C. A. (2017). Extensive listening in a Colombian university: Process, product, and perceptions. HOW, 24(1), 101-121. http://dx.doi.org/10.19183/how.24.1.311. 
Mayring, P. (2000). Qualitative content analysis. Forum Qualitative Research. Retrieved from $\mathrm{http} / /$ www.qualitative-research.net/fqs-texte/2-00/2-00mayring-e.pdf

Nation, I. S., \& Newton, J. (2008). Teaching ESL/EFL listening and speaking. Routledge.

Onoda, S. (2012). The effect of QuickListens and extensive listening on EFL listening skill development. (2012). Extensive Reading World Congress Proceedings, 1, 176-179.

Oxford, R. L. (2011). Teaching and researching: Language learning strategies. London, UK: Pearson.

Purdy, M. (1997). What is listening? In M. Purdy, \& D. Borisoff (Eds.)., Listening in everyday life: A personal and professional approach (2nd ed., pp. 1-20). Lanham, MD: University Press of America.

Reinders, H., Cho, M.Y. (2010). Extensive listening practice and input enhancement using mobile phones: Encouraging out-of-class learning with mobile phones. TESL - EJ. 14(2).

Renandya, W. A., \& Farrell, T. S. C. (2011). "Teacher, the tape is too fast": Extensive listening in ELT. ELT Journal, 65(1), 52-59.

Renandya, W. A. (2012). Materials and methods for extensive listening. In TEFLIN conference, Surabaya, Indonesia. Retrieved from https://www.academia.edu/2462863/Materials_and_Methods_for_Extensive_Listening.

Richards, J. \& Renandya, W. A. (2002). Methology in Language teaching: An Anthology of Current Practice. Cambridge: Cambridge University Press.

Riddell, D. (2003). Teaching English as a foreign language. London: Hodder Headline Ltd.

Rixon, S. (1986) Developing listening skills.London. Macmillan

Rost, M. (1994). Introducing listening. London: Penguin books.

Rost, M. (2002). Teaching and researching listening. Great Britain: Pearson Education

Sanders, J. R. (1981). Case study methodology: A critique. In Case study methodology in educational evaluation. Proceedings of the 1981 Minnesota Evaluation Conference. Minneapolis: Minnesota Research and Evaluation Center.

Schmidt, A. (2016). Listening journals for extensive and intensive listening practice. English Teaching Forum, 54(2), 2-11.

Siegel, J. (2011). Thoughts on L2 listening pedagogy. ELT Journal 65(3), 318-321.

Ucan, J. L. B. (2010). Benefits of using extensive listening in ELT. Memorias del vi foro de estudios en lenguas internacional, 36-44.

Vo, Y. (2013). Developing extensive listening for EFL learners using Internet resources. Hawaii Pacific University TESOL Working Paper Series. 11, 29-51.

Waring, R. (2008). Starting an extensive listening program. Extensive Reading in Japan: The Journal of the JALT ExtensiveReading Special Interest Group, www.robwaring.org/el/articles/Starting_Extensive_Listening_ERJ_June_2008.pdf

Waring, R. (2010). Extensive listening. Rob Waring's Websites. Personal website. Re-trieved from http://www.robwaring.org/el/

Widodo, H. P., \& Rozak, R. R. (2016). Engaging Student Teachers in Collaborative and Reflective Online VideoAssisted Extensive Listening in an Indonesian Initial Teacher Education (ITE) Context. Electronic Journal of Foreign Language Teaching, 13(2), 229-244.

Yeh, C. C. (2017). An investigation of a podcast learning project for extensive listening. Asian-Focused ELT Research and Practice: Voices from the Far Edge, 87. 


\section{Appendices}

\section{Appendix 1}

Listening Worksheet Template for Videos

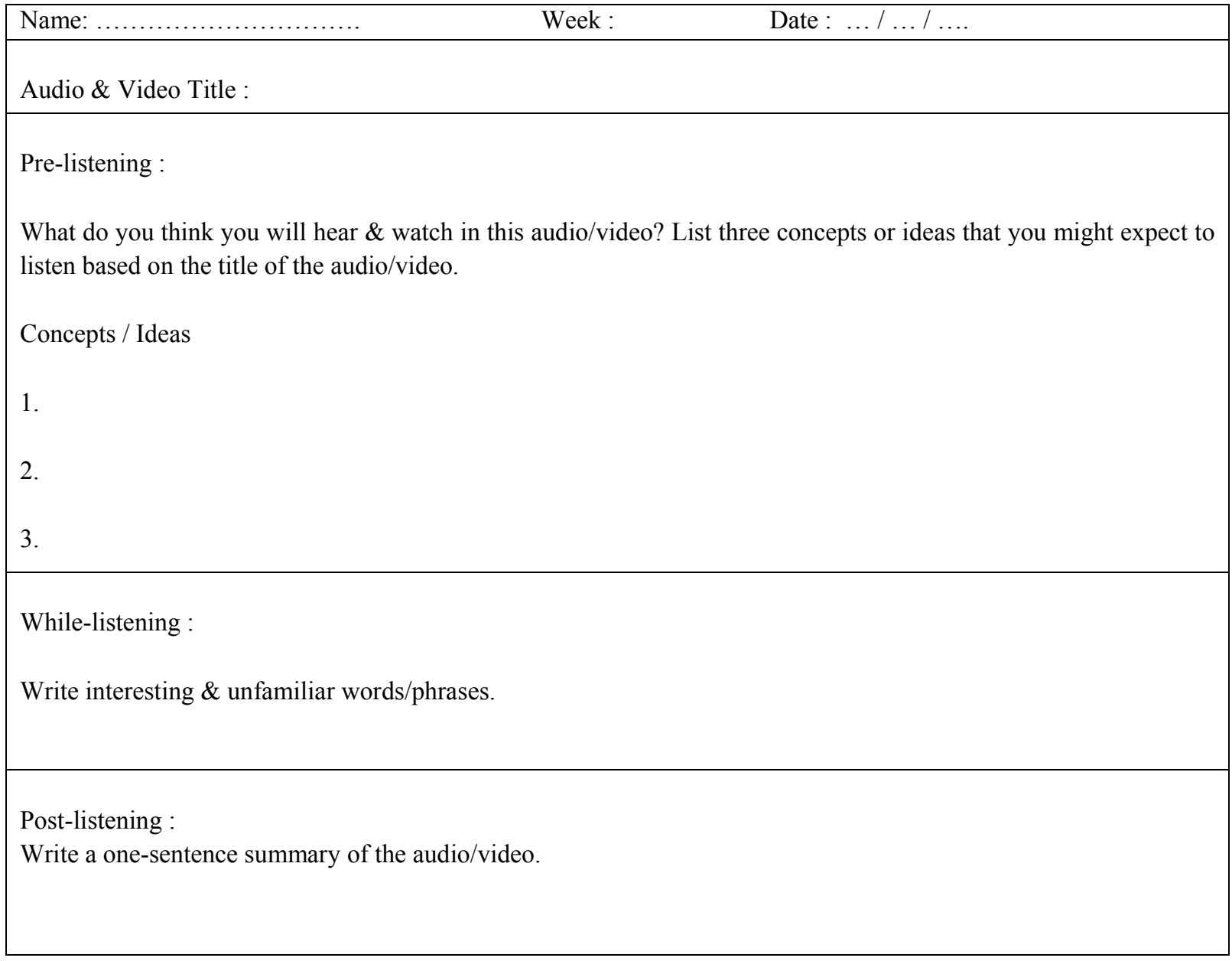

\section{Appendix 2}

\section{Interview Questions}

Name:

Gender and Age:

1. What do you think about listening out of the classroom?

2. Please describe your extensive listening process with three adjectives.

3. How do you think extensive listening and the activities which you completed after listening have affected your language learning? 